\title{
Controlled Synthesis and Characterization of Noble Metal Nanoparticles
}

\author{
Huixiao Hei, Hong He*, Rui Wang, Xiaojun Liu, Guizhen Zhang \\ Department of Chemistry and Chemical Engineering, Beijing University of Technology, Beijing, China. \\ Email: "hehong@bjut.edu.cn
}

Received March $1^{\text {st }}, 2012$; revised April $6^{\text {th }}, 2012$; accepted April 17 $7^{\text {th }}, 2012$

\begin{abstract}
In this work, monodispersed, well-shaped platinum $(3.2-6.4 \mathrm{~nm})$, rhodium $(2.4-5.1 \mathrm{~nm})$, and palladium $(3.2-5.3 \mathrm{~nm})$ nanoparticles capped with poly(vinylpyrrolidone) (PVP) were synthesized by a polyol reduction method in an ethylene glycol solution at temperature of $190^{\circ} \mathrm{C}$. The influences of synthetic parameters on the size and morphology of the noble metal nanoparticles have been systematically investigated. The noble metal nanoparticles were characterized by means of UV-vis, laser scattering particle size distribution analysis (LSPSDA) and transmission electron microscopy (TEM). The experimental results showed that the particle size of metal nanoparticles, the morphology of which was spherical, increased with the raise of metal precursor concentration as well as the amount of PVP. The optimal molar ratio of $\mathrm{PVP} /$ metal and metal precursor concentration for the fabrication of $\mathrm{Pt}, \mathrm{Rh}$, and $\mathrm{Pd}$ nanoparticles with uniform distribution were 10 and $0.1 \mathrm{mM}$, respectively. The morphologies of the $\mathrm{Rh}$ nanoparticles with the size of $5.1 \mathrm{~nm}$ were polygons, including hexagons, pentagons, and triangles.
\end{abstract}

Keywords: Polyol Reduction; Pt; Rh; Pd Nanoparticles; Poly(vinylpyrrolidone)

\section{Introduction}

Noble metal nanoparticles (NPs) with a narrow size distribution are valuable technological importance because of their unique physi-chemical properties and applications in the fields of catalysis, information storage, optoelectronics, sensors, fine chemicals synthesis, oil refining processes, and fuel cell technology. Uniformity of particle size minimizes the dispersion of important properties that are critical in these operations, such as surface chemical activity and magnetic as well as electronic properties [1-7]. Thus, much attention has been paid in recent years to develop methods of synthesizing monodispersed and size/shape controlled noble metal nanoparticles (Pt [8-10], Rh [11-13], Pd [14,15], Ir [16], $\mathrm{Au}$ $[17,18]$, and $\mathrm{Ag}[19,20])$ by tuning the particle growth kinetics in the processes of fabricating. Recent years, many effective methods have been developed including seeded growth by polyol reduction [21], thermolysis of organometallics [22], modified polyol methods [23], and micelle techniques [24]. Since Pt, $\mathrm{Rh}$, and Pd are important noble metals, the synthesis of the noble metal nanoparticles with size and shape regulated has thus become a fundamental research focus. For instance, Somorjai $[11,21]$ reported that the $\mathrm{Rh}$ nanocrystals with morphologies of multipod, cube, horn, and cuboctahedra were synthesized successfully by the seeded growth in a

\footnotetext{
${ }^{*}$ Corresponding author.
}

polyol system. Xia and co-workers [23] investigated the synthesis and stability of Rh multipods in a polyol system, which showed interesting surface plasmonic properties. By an organometallic approach, Son and co-workers [22] prepared monodispersed oleyl amine-capped $\mathrm{Rh}$ tetrahedral nanocrystals, which displayed excellent arenes hydrogenation activities. Mukul [25] had demonstrated 1D nanostructures composed of Rh (0) and Rh (I) prepared by solution-phase synthetic approach. However, there was little work on the systematically investigation of size control in fabricating monodispersed $\mathrm{Pt}, \mathrm{Rh}$, and Pd nanoparticles.

In this paper, we report a one-step polyol synthesis of monodispersed, well-shaped Pt $(3.2-6.4 \mathrm{~nm}), \mathrm{Rh}(2.4$ $5.1 \mathrm{~nm})$, and $\mathrm{Pd}(3.2-5.3 \mathrm{~nm})$ nanoparticles at temperature of $190^{\circ} \mathrm{C}$ in a polyol system, using ethylene glycol as the reducing solvent and poly(vinylpyrrolidone) as the capping agent. The varieties of particle size with an increasing in precursor concentration and the ratio of metal/PVP were illustrated. Especially, Rh nanoparticles in a smaller size $(5.1 \mathrm{~nm})$ were polygons, such as hexagons, pentagons, and triangles. The size of the Rh nanoparticles is smaller than that reported before.

\section{Experimental}

\subsection{Chemicals and Reagents}

Hexachloroplatinum Acid Hydrate $\left(\mathrm{H}_{2} \mathrm{PtCl}_{6} \cdot 6 \mathrm{H}_{2} \mathrm{O}, 99.9 \%\right)$, 
rhodium (III) chloride hydrate $\left(\mathrm{RhCl}_{3} \cdot 3 \mathrm{H}_{2} \mathrm{O}, 99.9 \%\right)$, and palladium (II) chloride $\left(\mathrm{PdCl}_{2}, 99.9 \%\right)$ were purchased from Shanghai Jiuling Chemical Co., Ltd. Poly(vinylpyrrolidone) $(\mathrm{PVP}, \mathrm{Mw}=300,000)$ and ethylene glycol (EG, 99.0\%) were received from Sinopharm Chemical Reagent Co., Ltd., the former was used as a stabilizer and the later was employed as the solvent and the reducing agent. All solvents (acetone and ethanol were used for rinsing) were analytical grade and used as received without further purification. All glassware were cleaned by using aqua-regia, subsequently rinsed with a plentiful amount of double-distilled water, and dried well prior to use.

\subsection{Synthesis of PVP-Capped Pt, Rh, and Pd Nanoparticles}

For synthesis of PVP-capped $\mathrm{Rh}$ nanoparticles, given amounts of $\mathrm{RhCl}_{3}(0.004-0.128 \mathrm{mmol})$ and PVP (0.04 $1.28 \mathrm{mmol})$ at a fixed $\mathrm{Rh} / \mathrm{PVP}$ ratio of $1: 10$ were dissolved in $40 \mathrm{~mL}$ of EG. The solution was heated to $130^{\circ} \mathrm{C}$ under stirring and was evacuated at this temperature for $20 \mathrm{~min}$ to remove water and oxygen, resulting in an optically transparent orange-yellow solution and then heated to the desired reaction temperature of $190^{\circ} \mathrm{C}$, as well as maintained at this temperature for $2 \mathrm{~h}$ under $\mathrm{N}_{2}$ atmosphere. During the reaction, the color of the solution gradually turned from orange-yellow to black. When the reaction was complete, an excess of acetone was poured into the solution at room temperature to form a cloudy black suspension. This suspension was separated by centrifugation at $4000 \mathrm{rpm}$ for $10 \mathrm{~min}$, and the black product was collected by discarding the colorless supernatant liquor. The precipitated $\mathrm{Rh}$ nanoparticles were washed with acetone and then redispersed in ethanol in a threenecked flask at room temperature. Pt nanoparticles were also prepared by using the same method, but instead of using PVP (0.04 - $1.92 \mathrm{mmol})$ dissolved in $40 \mathrm{~mL}$ of $\mathrm{H}_{2} \mathrm{PtCl}_{6}(0.004-0.192 \mathrm{mmol})$ in $\mathrm{EG}$ as starting materials.

For the synthesis of $\mathrm{Pd}$ nanoparticles, an aqueous solution of $\mathrm{H}_{2} \mathrm{PdCl}_{4}(50 \mathrm{mM})$ was prepared by completely dissolving $177.3 \mathrm{mg} \mathrm{PdCl} 2$ in $100 \mathrm{~mL}$ of $20 \mathrm{mM} \mathrm{HCl}$ in a boil water bath. $40 \mathrm{~mL} \mathrm{H}_{2} \mathrm{PdCl}_{4}$ aqueous solutions with different $\mathrm{Pd}$ ions concentrations $(0.12 \mathrm{mM}, 0.24 \mathrm{mM}$, $0.48 \mathrm{mM}, 0.96 \mathrm{mM}, 1.92 \mathrm{mM}, 3.84 \mathrm{mM})$ and desired amount of PVP $(0.05-3.0 \mathrm{mmol})$ were prepared in a three-necked flask. The rest of process is the same as the $\mathrm{Pt}$ and $\mathrm{Rh}$ nanoparticles preparation.

\subsection{Characterization}

The TEM images of the Pt, Rh, and Pd nanoparticles were collected on a transmission electron microscope (JEOL JEM-2100F and JEM-2010) operated at $200 \mathrm{kV}$. The shape and size of the nanoparticles were analyzed according to the images. The TEM samples were prepared by placing a drop of $\mathrm{Pt}, \mathrm{Rh}$, and $\mathrm{Pd}$ nanoparticles dispersed in ethanol onto a continuous carbon-coated copper grid.

The UV-vis absorption spectra of the samples were measured on a Shimadzu UV-2450 (200 - $800 \mathrm{~nm})$ equipped with a $1 \mathrm{~cm}$ path length quartz cuvette.

The particle size distribution was measured with a Laser Scattering Particle Size Distribution Analyzer (PSSNICOMP 380 ZLS). The test of nanocolloid was conducted at $25^{\circ} \mathrm{C}$. The samples were redispersed in ethanol, hence the liquid viscosity was set to $1.200 \mathrm{cp}$, and the liquid index of refraction was 1.359. Then there were two cycle tests for each sample. Based on the specific calculated results, the particle size distribution curves were given as seen in this paper.

\section{Results and Discussion}

\subsection{UV-Vis Spectra of Pt, Rh, and Pd Nanoparticles}

$\mathrm{UV}$-vis Spectrum is an effective method to investigate whether the metal precursors are completely reduced or not $[12,13]$. The UV-vis spectra of $\mathrm{H}_{2} \mathrm{PtCl}_{6}, \mathrm{RhCl}_{3}$, and $\mathrm{H}_{2} \mathrm{PdCl}_{4}$ solutions were recorded before the reduction. The results are showed in Figure 1. For the solution of $\mathrm{H}_{2} \mathrm{PtCl}_{6}$, there was an obviously absorption peak at 295 $\mathrm{nm}$ with a weak peak at $342 \mathrm{~nm}$. Three absorption peaks at 288, 253 and $475 \mathrm{~nm}$ as well as at 287, 324, and 434 nm could be observed over the $\mathrm{RhCl}_{3}$ and $\mathrm{H}_{2} \mathrm{PdCl}_{4}$ solutions, respectively, which could be attributed to the charge transfer from the ligand of $\mathrm{Cl}^{-}$to $\mathrm{Pt}^{4+}, \mathrm{Rh}^{3+}$, and $\mathrm{Pd}^{2+}$ ions in solution. The UV-vis spectra of the reaction system were measured after refluxing the EG solution of metal ions in the presence of PVP and shown on Figures 2 and 3. No significant absorption peak was found on the spectra displayed on Figures 2 and 3, indicating that all of the metal ions were reduced completely.

\subsection{The Influence of Precursor Concentration}

The particle size distributions were evaluated by the TEM experiments and laser scattering particle size distribution analysis. The TEM images of the Pt, $\mathrm{Rh}$ and $\mathrm{Pd}$ colloids were summarized on Figures 4-6, from which one can found that $\mathrm{Pt}, \mathrm{Rh}$, and $\mathrm{Pd}$ nanoparticles were dispersed uniformly with morphology of sphere shape and a narrow size distribution. The insets in Figures 4-6 are the corresponding size distributions obtained from the statistics of TEM images by counting about 100 particles.

From Figures 4-6, one can see that, at a given reaction temperature, the size of the $\mathrm{Pt}, \mathrm{Rh}$, and $\mathrm{Pd}$ nanoparticles could be tuned by changing the concentrations of $\mathrm{H}_{2} \mathrm{PtCl}_{6}$, 


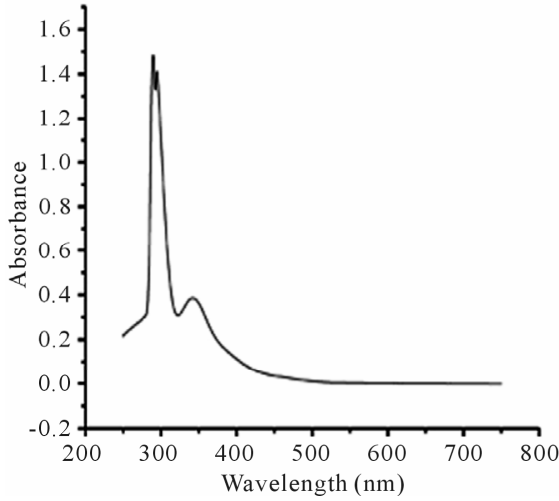

(a)

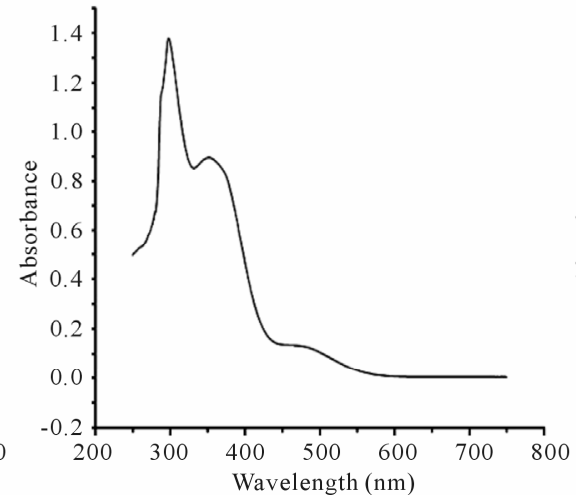

(b)

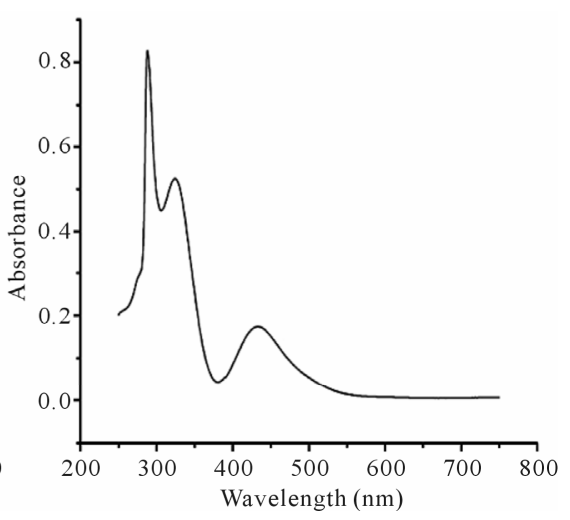

(c)

Figure 1. UV-vis spectra of $\mathbf{H}_{2} \mathrm{PtCl}_{6}(\mathrm{a}) ; \mathrm{RhCl}_{3}(\mathrm{~b})$ and $\mathrm{H}_{2} \mathrm{PdCl}_{4}$ (c) solutions.

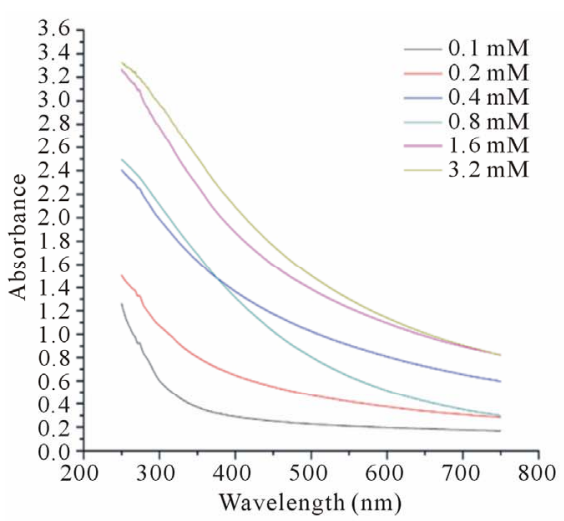

(a)

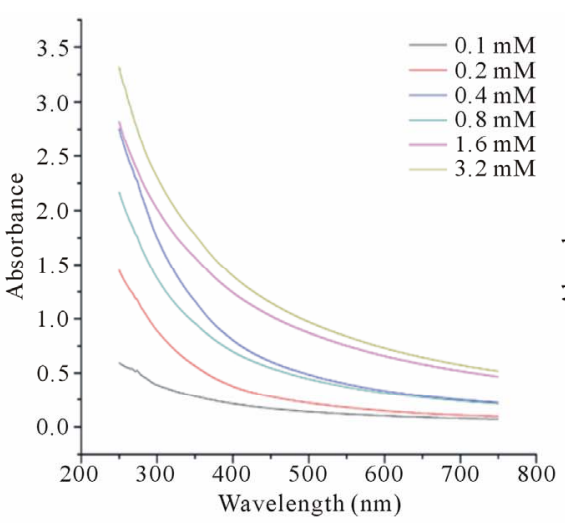

(b)

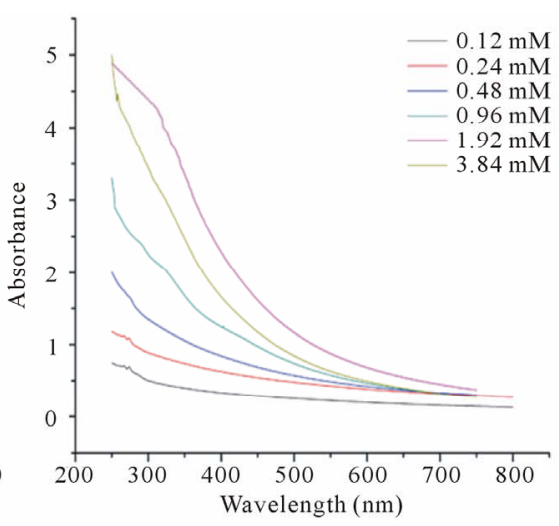

(c)

Figure 2. UV-vis spectra of $\mathrm{Pt}, \mathrm{Rh}, \mathrm{Pd}$ nanoparticles prepared on different concentration of $\mathrm{H}_{2} \mathrm{PtCl}_{6}(\mathrm{a}) ; \mathrm{RhCl}_{3}(\mathrm{~b})$ and $\mathrm{H}_{2} \mathrm{PdCl}_{4}$ (c) solutions.

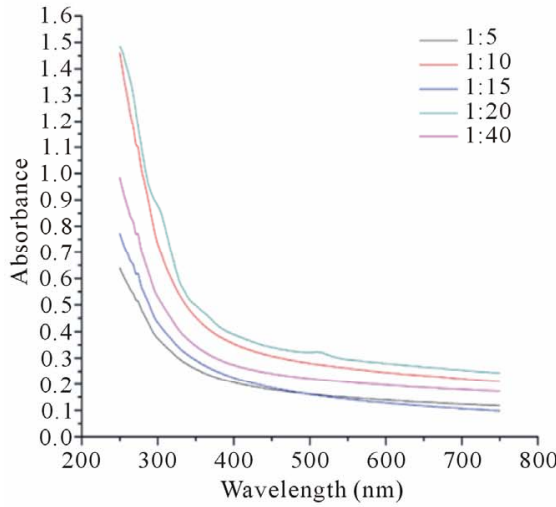

(a)

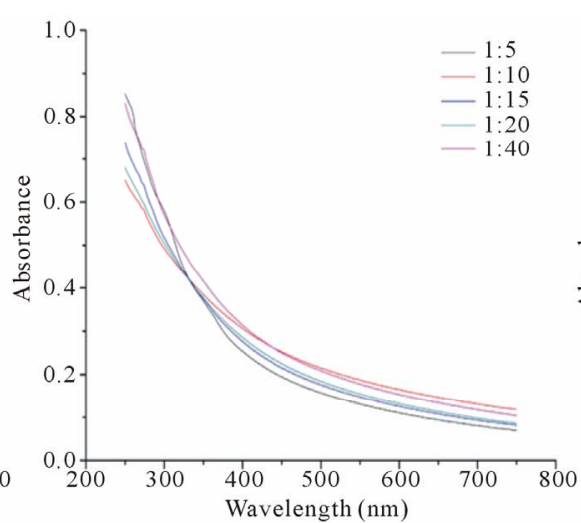

(b)

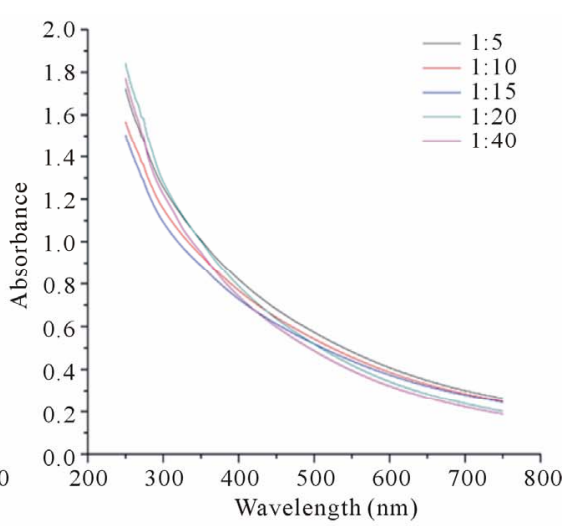

(c)

Figure 3. UV-vis spectra of Pt, Rh, Pd nanoparticles prepared with different ratios of Pt/PVP (a); Rh/PVP (b) and Pd/PVP (c).

$\mathrm{RhCl}_{3}$, and $\mathrm{H}_{2} \mathrm{PdCl}_{4}$. For example, at $190^{\circ} \mathrm{C}$ with $\left[\mathrm{RhCl}_{3}\right]$ $=0.1 \mathrm{mM}$, the average size of $\mathrm{Rh}$ nanoparticles was 2.4 nm (Figure 5(a)).

As the concentration of $\mathrm{RhCl}_{3}$ increased to $0.2 \mathrm{mM}$, the size of $\mathrm{Rh}$ nanoparticles increased to $2.7 \mathrm{~nm}$ with the better monodispersion (Figure 5(b)). In the $\mathrm{RhCl}_{3}$ concentration range of 0.1 to $3.2 \mathrm{mM}$, the $\mathrm{Rh}$ nanoparticles size enlarged as the $\mathrm{RhCl}_{3}$ concentration increased. $\mathrm{Rh}$ nanoparticles with a mean diameter of $2.4 \mathrm{~nm}$ (Figure 5(a)), $2.7 \mathrm{~nm}$ (Figure 5(b)), $2.9 \mathrm{~nm}$ (Figure 5(c)), 3.2 nm (Figure 5(d)), $4.0 \mathrm{~nm}$ (Figure 5(e)), and $5.1 \mathrm{~nm}$ (Figure 5(f)) were synthesized with the $\mathrm{RhCl}_{3}$ concentration of $0.1,0.2,0.4,0.8,1.6$, and $3.2 \mathrm{mM}$, respectively. Similarly, Pd nanoparticles with a mean diameter of 3.2 

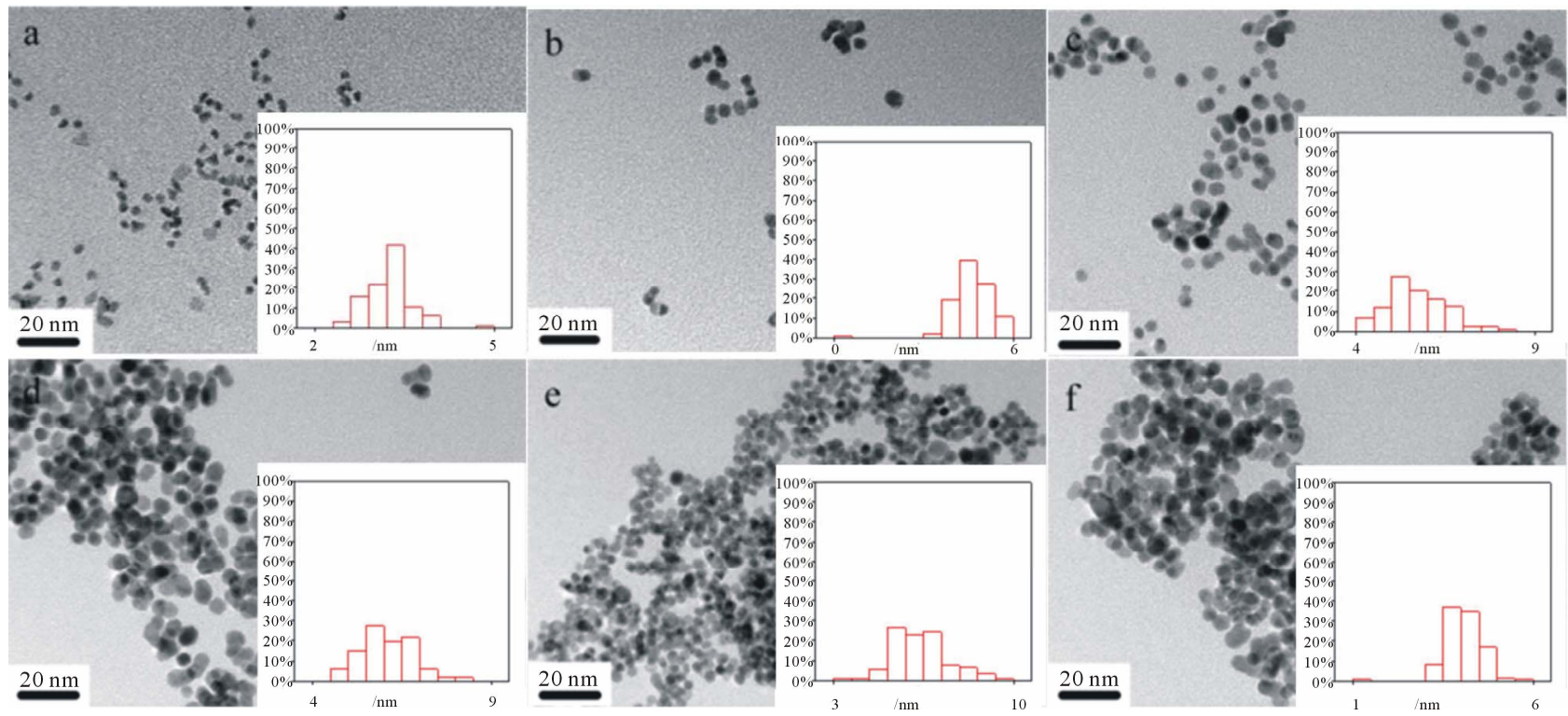

Figure 4. TEM images and the corresponding size distributions of Pt nanoparticles synthesized at the $\mathrm{H}_{2} \mathrm{PtCl}_{6} \mathrm{Concentration}$ of $0.1 \mathrm{mM}$ (a); $0.3 \mathrm{mM}$ (b); $0.6 \mathrm{mM}$ (c); $1.2 \mathrm{mM}$ (d); $2.4 \mathrm{mM}$ (e) and $4.8 \mathrm{mM}$ (f).
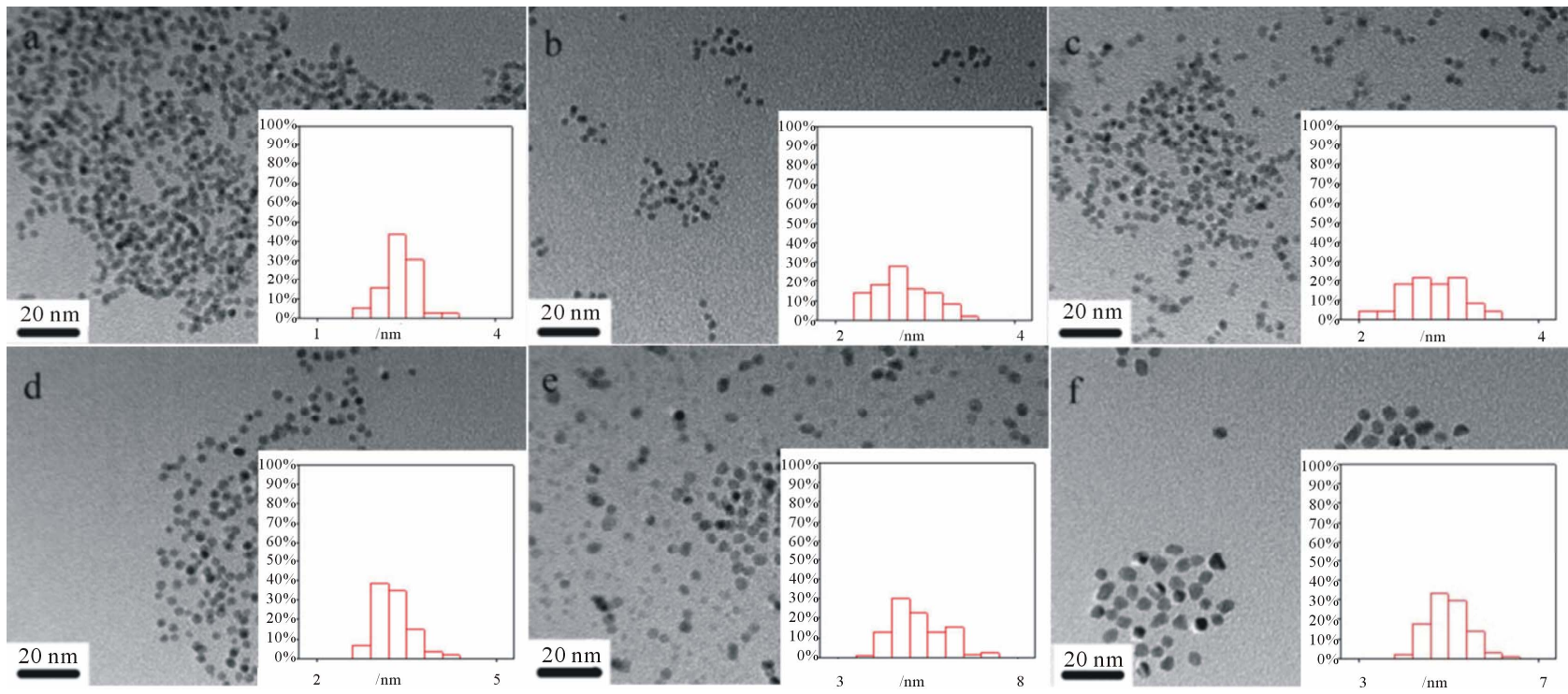

Figure 5. TEM images and the corresponding size distributions of Rh nanoparticles synthesized at the $\mathbf{R h C l}_{3}$ concentration of $0.1 \mathrm{mM}$ (a); $0.2 \mathrm{mM}$ (b); $0.4 \mathrm{mM}$ (c); $0.8 \mathrm{mM}$ (d); $1.6 \mathrm{mM}$ (e) and $3.2 \mathrm{mM}$ (f).

$\mathrm{nm}$ (Figure 6(a)), $3.3 \mathrm{~nm}$ (Figure 6(b)), $4.0 \mathrm{~nm}$ (Figure 6(c)), $4.4 \mathrm{~nm}$ (Figure 6(d)), $4.8 \mathrm{~nm}$ (Figure 6(e)), and $5.3 \mathrm{~nm}$ (Figure 6(f)) were synthesized with the $\mathrm{H}_{2} \mathrm{PdCl}_{4}$ concentration of $0.12,0.24,0.48,0.96,1.92$, and 3.48 $\mathrm{mM}$ as well as the Pt nanoparticles with a mean diameter of $3.2 \mathrm{~nm}$ (Figure 4(a)), $4.6 \mathrm{~nm}$ (Figure 4(b)), $5.7 \mathrm{~nm}$ (Figure 4(c)), $6.1 \mathrm{~nm}$ (Figure 4(d)), and $6.4 \mathrm{~nm}$ (Figure 4(e)) were synthesized with the $\mathrm{H}_{2} \mathrm{PtCl}_{6}$ concentration of $0.1,0.3,0.6,1.2$, and $2.4 \mathrm{mM}$, respectively.

The average particle size of $\mathrm{Pt}, \mathrm{Rh}$, and $\mathrm{Pd}$ nanoparticles measured by laser scattering particle size distribution analysis was shown in Table 1. Group (a) was referred to the concentration of $\mathrm{Pt}, \mathrm{Rh}$ and $\mathrm{Pd}$ precursors, which was consistent with that shown in Figures 4(a), 5(a) and 6(a). Similarly, the concentrations of Group (b), (c), (d), (e) and (f) were also referred to that in Figures 4-6, respectively. It could be seen that the average sizes obtained by Laser Scattering Particle Size Distribution Analyzer were larger than those given by TEM images. This may be attributed to two reasons: 1) it was due to the metal nanoprticles attached with capping agent, which would take deviations towards larger sizes; 2) the size distributions here was referred to the aggregated particles, also called the particle reunion. Though the software has a function 


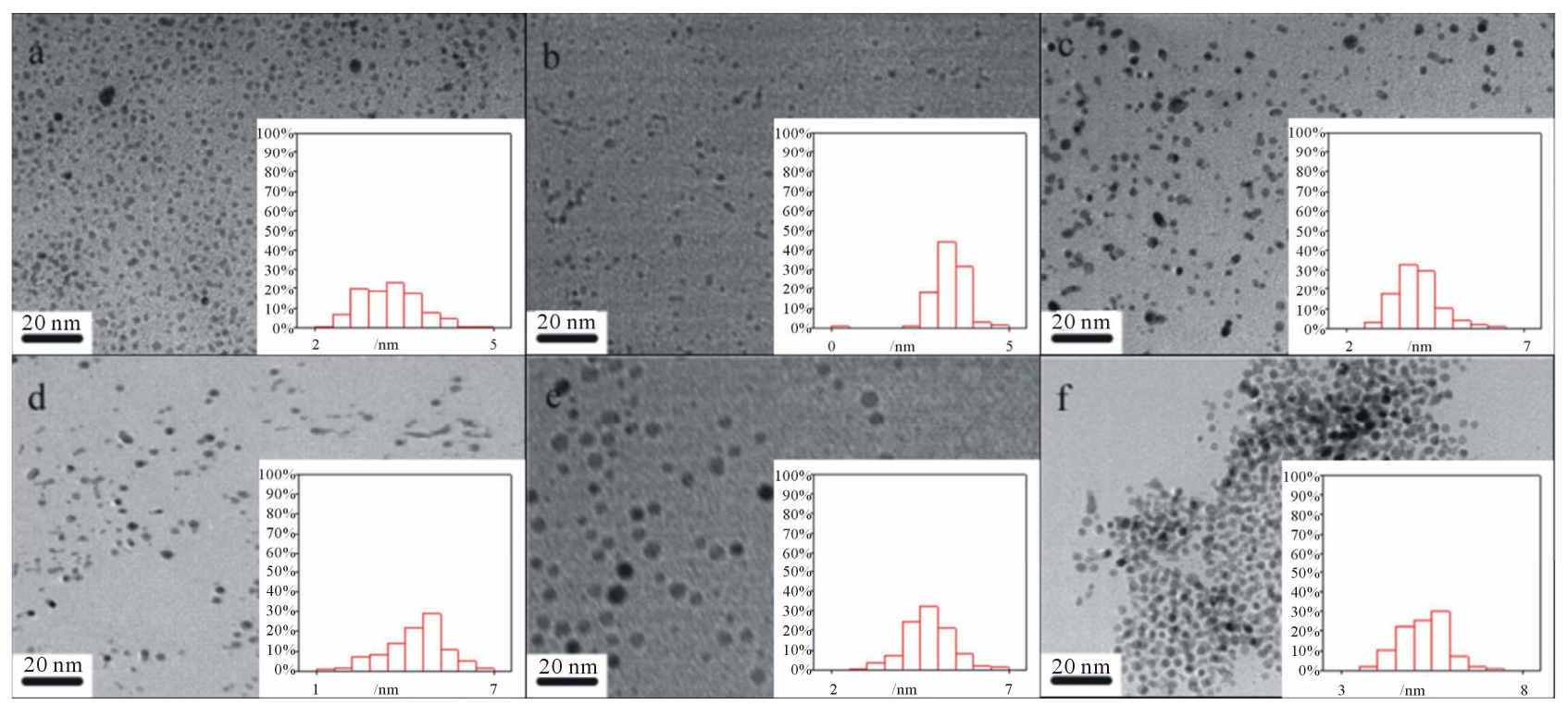

Figure 6. TEM images and the corresponding size distributions of $\mathrm{Pd}$ nanoparticles synthesized at the $\mathrm{H}_{2} \mathrm{PdCl}_{4} \mathrm{Concentration}$ of $0.12 \mathrm{mM}$ (a); $0.24 \mathrm{mM}$ (b); $0.48 \mathrm{mM}$ (c); $0.96 \mathrm{mM}$ (d); $1.92 \mathrm{mM}$ (e) and $3.84 \mathrm{mM}$ (f).

Table 1. The average particle size of $\mathrm{Pt}, \mathrm{Rh}$, and Pd nanoparticles measured by laster scattering particle size distribution analysis (I) and TEM (II), respectively.

\begin{tabular}{ccccccc}
\hline \multirow{2}{*}{ Group } & \multicolumn{3}{c}{ Particle size/nm (I) } & \multicolumn{3}{c}{ Particle size/nm (II) } \\
\cline { 2 - 7 } & Pt NPs & Rh NPs & Pd NPs & Pt NPs & Rh NPs & Pd NPs \\
\hline a & 28.6 & 11.1 & 18.3 & 3.2 & 2.4 & 3.2 \\
b & 5.0 & 2.8 & 4.0 & 4.6 & 2.7 & 3.3 \\
c & 5.8 & 3.5 & 10.3 & 5.7 & 3.9 & 4.0 \\
d & 10.4 & 7.2 & 13.3 & 6.1 & 4.2 & 4.4 \\
e & 15.1 & 12.1 & 13.9 & 6.4 & 4.0 & 4.8 \\
f & 9.4 & 15.9 & 14.1 & 4.1 & 5.1 & 5.3 \\
\hline
\end{tabular}

to eliminate the influence by the particle aggregation, the reunion effect still existed as a result of the inter-molecular force.

However, it was more intuitive and accurate to obtain the particle size distribution with TEM images. One can obtain the size distribution, as well as the shape, structure and surface textile information of the particles over the TEM results.

In the process of the noble metal nanoparticles fabrication, the initially formed metal atoms self nucleated to form a fixed number of seeds during the first stage of the reaction, and the particles then continued to grow by diffusion-driven deposition of metal atoms onto the existing seeds. High noble metal precursor concentration leaded to fast reduction at given temperature and a decrease in the reduction temperature, i.e. the temperature of the orange-yellow solution becoming to black color in our experiments. For instance, the reduction rate of $\mathrm{Rh}^{3+}$ be- came slow at low $\mathrm{RhCl}_{3}$ concentration and the consumption of $\mathrm{Rh}$ atoms decreased during particles growth, resulting in the production of smaller Rh nanoparticles. Therefore, the size of $\mathrm{Rh}$ nanoparticles increased with the increasing $\mathrm{RhCl}_{3}$ concentration in the range of $0.1-3.2$ $\mathrm{mM}$. The optimal metal precursor concentration for the fabrication of $\mathrm{Rh}$ nanoparticles with smaller uniform distribution was $0.1 \mathrm{mM}$. The similar phenomena were also observed as the $\mathrm{Pd}$ and $\mathrm{Pt}$ nanoparticles were synthesized. The same result can be found in the report given by Zhang [12].

However, as the concentrations of metal precursor were much high, the reduction rate of metal ions would be accelerated to generate too many metal atoms with zero valence in a short period of time, leading in size polydispersity for metal nanoparticles $[12,13]$. It is found that when the concentration of $\mathrm{H}_{2} \mathrm{PtCl}_{6}$ increased to $4.8 \mathrm{mM}$, the $\mathrm{Pt}$ nanoparticles became smaller in average size and 
the aggregations of particle began to appear. For example, as for the $\mathrm{Pt}$ nanoparticles fabrication, as the concentration of $\mathrm{H}_{2} \mathrm{PtCl}_{6}$ was enhanced to $4.8 \mathrm{mM}$, the size of $\mathrm{Pt}$ nanoparticles decreased to $4.1 \mathrm{~nm}$ (Figure 4(f)).

\subsection{The Influence of Metal/PVP Ratio}

Besides the concentration of metal precursor, the amount of capping agent, such as PVP, and the ratio of metal/ PVP also have significant effects on the size and morphology of the metal nanoparticles prepared by the polyol reduction. According to the effect of concentration, we know that the optimal metal precursor concentration for the fabrication of $\mathrm{Pt}, \mathrm{Rh}$, and $\mathrm{Pd}$ nanoparticles with uniform distribution and relatively small size was $0.1 \mathrm{mM}$. At the fixed metal precursors concentration and reduction temperature, the investigation for the effects of the amount of PVP on the preparation of the $\mathrm{Pt}, \mathrm{Rh}$, and $\mathrm{Pd}$ nanoparticles were also carried out. Based on the results of size measurement over a LSPSDA, the relationships between the size of metal nanoparticles and the ratio of $\mathrm{Pt} / \mathrm{PVP}, \mathrm{Rh} / \mathrm{PVP}$, and $\mathrm{Pd} / \mathrm{PVP}$, which varied from 1:5 to 1:40, were summarized in Figure 7. It is clear that as the amount of PVP increased, the average particle size had a tendency to decrease firstly and then increase fast. It is consistent with other reports [26]. The optimal molar ratio of metal/PVP was $1: 10$. When the ratio of metal/PVP was larger than $1: 10$, the average size of the metal nanoparticles increased slightly. When the ratio of metal/PVP was smaller than $1: 10$, the particle size increased with the reducing of the metal/PVP ratio. PVP as an effective stabilizer and protecting agent can limit particle growth and prevent the particles from aggregation. But PVP also could induce the reduction of metal in ethylene glycol and speed up the kinetics of particle formation [26]. PVP and metal nanoparticles formed a complex

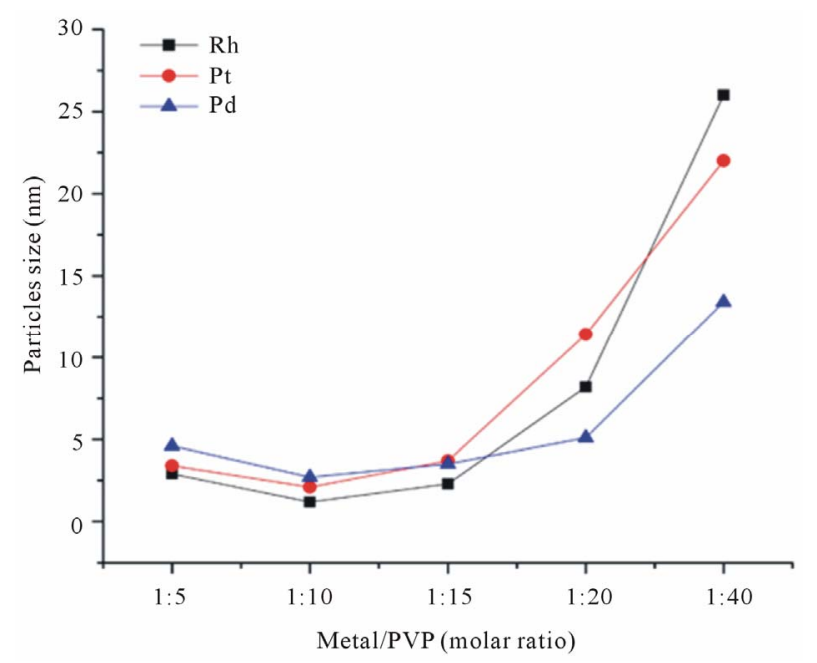

Figure 7. Particle-size curve respected to the ratio of $\mathrm{Pt}$ / PVP, Rh/PVP and Pd/PVP. by coordinate bonds between the surface sites of noble metal nanoparticles and $\mathrm{N}$ as well as $\mathrm{O}$ atoms of PVP, which resulted in a low concentration of free noble metal nanoparticles and a decrease in the electrode reduction potential of the metal ion, and then speeded up the reduction rate of metal ions as well as the consumption of metal atoms during particle growth process. As the concentration of PVP was excessive, it would restrain the diffusion of the metal nanoparticles. Therefore, the dispersion of the nanoparticles became more difficult and aggregation would be occurred again, leading to an increase in the metal nanoparticle size.

\section{Conclusion}

Using $\mathrm{H}_{2} \mathrm{PtCl}_{6}, \mathrm{RhCl}_{3}$, and $\mathrm{H}_{2} \mathrm{PdCl}_{4}$ as the metal precursors, PVP-capped Pt (3.2 - $6.4 \mathrm{~nm})$, Rh (2.4 - $5.1 \mathrm{~nm})$, and $\mathrm{Pd}(3.2-5.3 \mathrm{~nm})$ nanoparticles with a narrow particle size distribution were successfully synthesized in ethylene glycol at temperature of $190^{\circ} \mathrm{C}$ under $\mathrm{N}_{2}$. The size of the $\mathrm{Pt}, \mathrm{Rh}$, and $\mathrm{Pd}$ nanoparticles could be manipulated by varying the metal precursor concentration and the ratio of $\mathrm{PVP} /$ metal because of the well-controlled precursor reduction kinetics in the nucleation and particles growth stages. The polyol method has the merits of one-step synthesis, easy operation, and good reproducibility. Overall, it provides a good way for the size controlling of $\mathrm{Pt}, \mathrm{Rh}$, and $\mathrm{Pd}$ nanoparticles in solution. The optimal malor ratio of $\mathrm{PVP} / \mathrm{metal}$ and metal precursor concentration for the fabrication of $\mathrm{Pt}, \mathrm{Rh}$, and Pd NPs with uniform distribution were 10 and $0.1 \mathrm{mM}$, respectively.

\section{Acknowledgements}

This work was supported by NSFC (Natural Science Foundation of China) (20833011, 21007002), Beijing Municipal Natural Science Foundation (2101002), Beijing academic innovation team to plan projects (PHR201107104). We thank Dr. Wu, who conducted the TEM characterization of the samples.

\section{REFERENCES}

[1] G. A. Somorjai, "Introduction to Surface Chemistry and Catalysis," Wiley, New York, 1994.

[2] H. Song, F. Kim, S. Connor, G. A. Somorjai and P. Yang, "Pt Nanocrystals: Shape Control and Langmuir-Blodgett Monolayer Formation," The Journal of Physical Chemistry B, Vol. 109, No. 1, 2005, pp. 188-193.

[3] H. Song, R. M. Rioux, J. D. Hoefelmeyer, R. Komor, K. Niesz, M. Grass, P. Yang and G. A. Somorjai, "Hydrothermal Growth of Mesoporous SBA-15 Silica in the Presence of PVP-Stabilized Pt Nanoparticles: Synthesis, Characterization, and Catalytic Properties," Journal of the American Chemical Society, Vol. 128, No. 9, 2006, pp. 
3027-3037. doi:10.1021/ja057383r

[4] R. J. White, R. Luque, V. L. Budarin, J. H. Clark and D. J. Macquarrie, "Supported Metal Nanoparticles on Porous Materials. Methods and Applications," Chemical Society Reviews, Vol. 38, No. 2, 2009, pp. 481-494. doi:10.1039/b802654h

[5] Y. Wang and N. Herron, "Nanometer-Sized Semiconductor Clusters: Materials Synthesis, Quantum Size Effects, and Photophysical Properties," The Journal of Physical Chemistry, Vol. 95, No. 2, 1991, pp. 525-532. doi:10.1021/j100155a009

[6] D. Astruc, F. Lu and J. R. Aranzaes, "Nanoparticles as Recyclable Catalysts: The Frontier between Homogeneous and Heterogeneous Catalysis," Angewandte Chemie International Edition, Vol. 44, No. 48, 2005, pp. 78527872. doi:10.1002/anie. 200500766

[7] J. Song, D. Kim and D. Lee, " Size Control in the Synthesis of 1 - $6 \mathrm{~nm}$ Gold Nanoparticles via Solvent-Controlled Nucleation," Langmuir, Vol. 27, No. 22, 2011, pp. 13854-13860.

[8] R. M. Rioux, H. Song, M. Grass, S. Habas, K. Niesz, J. D. Hoefelmeyer, P. Yang and G. A. Somorjai, "Monodisperse Platinum Nanoparticles of Well-Defined Shape: Synthesis, Characterization, Catalytic Properties and Future Prospects," Topics in Catalysis, Vol. 39, No. 3-4, 2006, pp. 167-174. doi:10.1007/s11244-006-0053-2

[9] A. Chen and P. Holt-Hindle, "Platinum-Based Nanostructured Materials: Synthesis, Properties, and Applications," Chemical Reviews, Vol. 110, No. 6, 2010, pp. 37673804. doi: $10.1021 / \mathrm{cr} 9003902$

[10] Y. Bi and G. Lu, "Facile Synthesis of Platinum Nanofiber/Nanotube Junction Structures at Room Temperature," Chemistry of Materials, Vol. 20, No. 4, 2008, pp. 12241226. doi: $10.1021 / \mathrm{cm} 703093 \mathrm{~m}$

[11] S. M. Humphrey, M. E. Grass, S. E. Habas, K. Niesz, G. A. Somorjai and T. D. Tilley, "Rhodium Nanoparticles from Cluster Seeds: Control of Size and Shape by Precursor Addition Rate," Nano Letters, Vol. 7, No. 3, 2007 , pp. 785-790. doi:10.1021/n1070035y

[12] Y. Zhang, E. G. Grass, S. E. Habas, F. Tao, T. Zhang, P. Yang and G. A. Somorjai, "One-Step Polyol Synthesis and Langmuir-Blodgett Monolayer Formation of SizeTunable Monodisperse Rhodium Nanocrystals with Catalytically Active (111) Surface Structures," The Journal of Physical Chemistry C, Vol. 111, No. 33, 2007, pp. 1224312253. doi:10.1021/jp073350h

[13] Y. Borodko, H. S. Lee, H. Joo, Y. Zhang and G. A. Somorjai, "Spectroscopic Study of the Thermal Degradation of PVP-Capped $\mathrm{Rh}$ and Pt Nanoparticles in $\mathrm{H}_{2}$ and $\mathrm{O}_{2}$ Environments," Journal of Physical Chemistry C, Vol. 114, No. 2, 2010, pp. 1117-1126. doi:10.1021/jp909008z

[14] Y. Xiong, J. M. Mclellan, Y. Yin and Y. Xia, "Synthesis of Palladium Icosahedra with Twinned Structure by Blocking Oxidative Etching with Citric Acid or Citrate Ions," Angewandte Chemie International Edition, Vol. 46, No. 5, 2007, pp. 790-794. doi:10.1002/ange.200604032

[15] S. Xu and Q. Yang, "Well-Dispersed Water-Soluble Pd
Nanocrystals: Facile Reducing Synthesis and Application in Catalyzing Organic Reactions in Aqueous Media," Journal of Physical Chemistry C, Vol. 112, No. 35, 2008, pp. 13419-13425. doi:10.1021/jp800539x

[16] C. A. Stowell and B. A. Korgel, "Iridium Nanocrystal Synthesis and Surface Coating-Dependent Catalytic Activity," Nano Letters, Vol. 5, No. 7, 2005, pp. 1203-1207. doi:10.1021/n1050648f

[17] D. Seo, J. C. Park and H. Song, "Polyhedral Gold Nanocrystals with $\mathrm{O}_{\mathrm{h}}$ Symmetry: From Octahedra to Cubes," Journal of the American Chemical Society, Vol. 128, No. 46, 2006, pp. 14863-14870. doi:10.1021/ja062892u

[18] Q. Zhang, J. Xie, J. Yang and J. Y. Lee, "Monodisperse Icosahedral Ag, Au, and Pd Nanoparticles: Size Control Strategy and Superlattice Formation," ACS Nano, Vol. 3, No. 1, 2009, pp. 139-148. doi:10.1021/nn800531q

[19] A. Tao, P. Sinsermsuksakul and P. Yang, "Polyhedral Silver Nanocrystals with Distinct Scattering Signatures," Angewandte Chemie International Edition, Vol. 45, No. 28, 2006, pp. 4597-4601. doi:10.1002/anie.200601277

[20] B. Wiley, Y. Sun and Y. Xia, "Synthesis of Silver Nanostructures with Controlled Shapes and Properties," Accounts of Chemical Research, Vol. 40, No. 10, 2007, pp. 1067-1076. doi:10.1021/ar7000974

[21] J. D. Hoefelmeyer, K. Niesz, G. A. Somorjai and T. D. Tilley, "Radial Anisotropic Growth of Rhodium Nanoparticles," Nano Letters, Vol. 5, No. 3, 2005, pp. 435-438. doi:10.1021/n1048100g

[22] K. H. Park, K. Jang, H. J. Kim and S. U. Son, "NearMonodisperse Tetrahedral Rhodium Nanoparticles on Charcoal: The Shape-Dependent Catalytic Hydrogenation of Arenes," Angewandte Chemie International Edition, Vol. 46, No. 7, 2007, pp. 1152-1155. doi:10.1002/anie.200603961

[23] N. Zettsu, J. M. McLellan, B. J. Wiley, Y. Yin, Z. Y. Li and Y. Xia, "Synthesis, Stability, and Surface Plasmonic Properties of Rhodium Multipods, and Their Use as Substrates for Surface-Enhanced Raman Scattering," Angewandte Chemie International Edition, Vol. 118, No. 8, 2006, pp. 1310-1314. doi:10.1002/ange.200503174

[24] H. Lee, S. E. Habas, S. Kweskin, D. Butcher, G. A. Somorjai and P. Yang, "Morphological Control of Catalytically Active Platinum Nanocrystals," Angewandte Chemie International Edition, Vol. 118, No. 46, 2006, pp. 7988-7992. doi:10.1002/ange.200603068

[25] P. Mukul, S. Sougata and P. Tarasankar, "High-Yield Synthesis of 1D Rh Nanostructures from Surfactant Mediated Reductive Pathway and Their Shape Transformation," Journal of Physical Chemistry C, Vol. 114, No. 39, 2010, pp. 16129-16142. doi:10.1021/jp101585y

[26] F. Bonet, V. Delmas, S. Grugeon, R. H. Urbina, P-Y Silvert and K. Tekaia-Elhsissen, "Synthesis of Monodisperse $\mathrm{Au}, \mathrm{Pt}, \mathrm{Pd}, \mathrm{Ru}$ and Ir Nanoparticles in Ethylene Glycol," Nano Structured Materials, Vol. 11, No. 8, 1999 , pp. 1277-1284. doi:10.1016/S0965-9773(99)00419-5 